\title{
Differential distribution of annexins-I, -II, -IV, and -VI in synovium
}

\author{
N J Goulding, J Dixey, E F Morand, R A Dodds, L S Wilkinson, A A Pitsillides, \\ J C W Edwards
}

\begin{abstract}
Objectives-To examine the distribution of four annexins in non-inflamed rheumatoid arthritic and osteoarthritic synovial tissue.

Methods-Frozen sections were stained with monoclonal antibodies (MAb) specific for annexins-I, -II, -IV, and -VI, and for cell lineage related markers including CD68 and CD14 (macrophages), prolyl hydroxylase (fibroblasts), and CD3 (T cells).

Results-Each of the annexins was present in synovial tissues in significant amounts in the three groups studied. Annexin-I was predominantly found within the synovial lining layer and double labelling showed it to be present predominantly in cells of the macrophage lineage. In rheumatoid specimens there was increased staining within the lining layer, perivascularly and on macrophages within the tissue stroma. Annexin-II was present in a distribution similar to that of annexin-I, but with more prominent perivascular staining. Annexins-IV and -VI were seen chiefly in association with areas of lymphocyte infiltration in rheumatoid tissue, whereas annexins-I and -II were absent from these areas. Endothelial cells stained weakly positive for annexins-I and -II, and more strongly for -IV and -VI.

Conclusions-This study demonstrates that annexins (particularly annexin-I, a putative mediator of the anti-inflammatory activities of glucocorticoids) are abundant in rheumatoid and nonrheumatoid synovial tissue, annexins -IV and -VI having a distribution distinct from that of $-\mathrm{I}$ and $-\mathrm{II}$.
\end{abstract}

(Ann Rheum Dis 1995; 54: 841-845)

The corticosteroid hormones have both an endogenous and a pharmacological role in regulating inflammatory responses. Munck et $a l^{1}$ have proposed that the increase in plasma cortisol following a stress stimulus acts to prevent an excessive cascade of soluble mediators produced by cells at the site of injury or infection. Such a feedback mechanism would prevent excessive tissue destruction and self limit an inflammatory episode. Corticosteroids act through multiple pathways in suppressing inflammation and immune responses, ${ }^{2}$ but one potential mediator of some of the antiinflammatory effects of the corticosteroids has been isolated: annexin-I (also known as lipocortin-I) is a $37 \mathrm{kDa}$ protein and shares sequence homology with other calcium binding proteins which lack the classic EFhand motif for calcium binding; ${ }^{4}$ the protein is induced in response to corticosteroids both in vivo and in vitro, and has anti-inflammatory activities in several animal models. ${ }^{56}$ Perhaps the best evidence that this protein is involved in regulating inflammation comes from work in rats which demonstrated that adrenalectomy results in a diminution of the levels of both lipocortin-I mRNA and protein in epithelial tissues at discrete sites around the body. Levels of message and protein were restored to normal when animals received physiological doses of cortisone. $^{7}$

Impaired lipocortin-I responses appear to be associated with chronic inflammatory diseases. Rheumatoid leucocytes exhibit reduced lipocortin-I production in response to corticosteroid, ${ }^{8}$ and reduction in the level of specific lipocortin binding molecules on the surface of blood monocytes and polymorphonuclear cells. ${ }^{9}$ The annexin supergene family of calcium binding proteins has at least 11 other distinct members with diverse functions. Eight have been well characterised. Annexin-II (calpactin) has a role in exocytosis. ${ }^{10}$ AnnexinIII, -IV, and -VI are constitutively expressed in many cell types and appear to have an intracellular role as cytoskeletal elements in exocytosis and cell differentiation. ${ }^{11-13}$ Annexin-V and -VIII are vascular anticoagulants, ${ }^{14}$ and annexin-VII (synexin) may act as a calcium channel. ${ }^{15}$ Because of the reported antiinflammatory activity of lipocortin-I (annexin-I) we made an immunohistochemical assessment of the distribution of four different annexins in synovial tissues from RA, OA, and control subjects.

\section{Patients and methods}

Non-inflamed synovium was obtained from clinically and histologically normal joints of limbs from two patients undergoing amputation for osteosarcoma. Diseased synovium was obtained from four patients with osteoarthritis and six with rheumatoid arthritis (definite or classical by American College of Rheumatology criteria $^{16}$ ) undergoing arthroplasty, within 20 minutes of removal. Tissues were trimmed of fat, dissected into 3-5 mm pieces, snap frozen in $\mathrm{N}$-hexane at $-70^{\circ} \mathrm{C}$ and stored at $-70^{\circ} \mathrm{C}$ until required for sectioning. Sections $7 \mu \mathrm{m}$ thick were cut at $-35^{\circ} \mathrm{C}$ on a cryostat (Bright Instruments) and air dried at room temperature. 
Monoclonal antibodies raised against annexins were obtained from ICN Flow Ltd, UK (antiannexin-I clone A1; anti-P11 sub unit of annexin-II, clone LC148; antiannexin IV, clone CPIII-16; antiannexin-VI, clone 73-5-4), and as a generous gift from Biogen
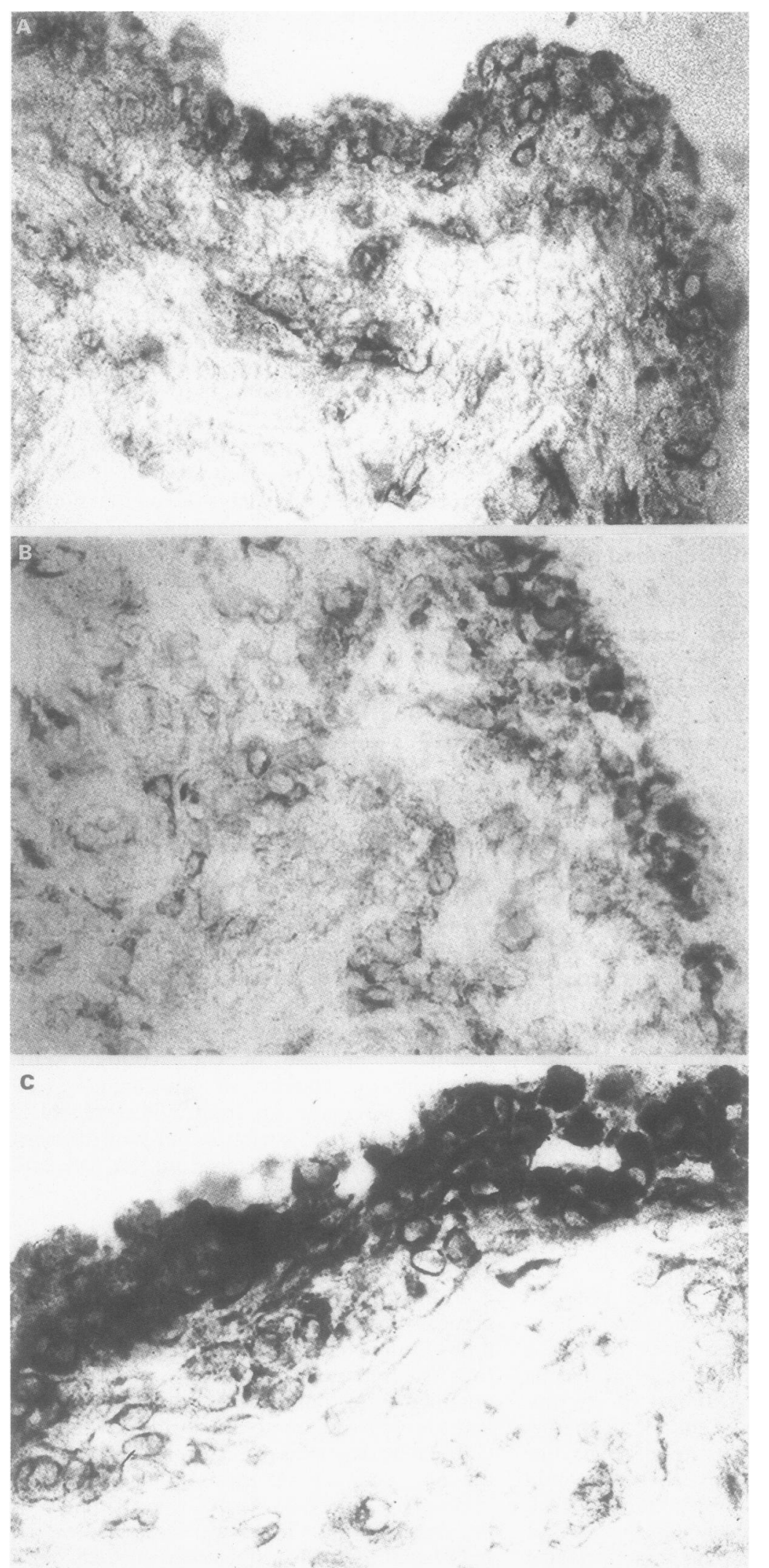

Figure 1 Distribution of annexin-I in non-counterstained sections of non-involved knee joint synovium from a patient with osteosarcoma $(A)$, osteoarthritic synovium $(B)$, and rheumatoid arthritic synovium (C).
Corp, Cambridge MA, USA (MAb 1B, antiannexin-I). Antibodies used for cell identification included EBM11 ${ }^{17}$ (anti-CD68) and anti-CD14 (for macrophage lineage cells), anti-CD3 (Wessex Regional Immunology Service) for $\mathrm{T}$ cells, and $5 \mathrm{~B} 5^{18}$ (antiprolylhydroxylase) for fibroblasts. Antibody P3 (Medarex, NJ, USA) with no known reactivity with human tissues was used to control for non-specific binding. Sections were fixed for 10 minutes in acetone at room temperature, washed in Tris buffered saline (TBS) $\mathrm{pH} 7 \cdot 6$ and incubated with primary antibody at optimal dilution in TBS for 30 minutes at room temperature. Slides were then washed twice in TBS and incubated with rabbit antimouse immunoglobulins $(1: 20)$ in TBS containing $20 \%$ normal human serum for 30 minutes at room temperature. After two further washes in TBS, the slides were incubated in mouse alkaline phosphatase (1:50) in TBS containing $20 \%$ normal human serum for 30 minutes at room temperature, and then developed using naphthol AS-MX phosphate in combination with fast red TR salt containing $0.1 \mathrm{~mol} / 1$ levamisole. Sections were finally counterstained with haematoxylin and mounted in Apathy's medium (BDH).

A separate series of double labelling experiments was performed using antibody A1 to annexin-I in combination with biotinylated anti-CD68. Tissues were prepared as above with the substitution of phosphate buffered saline (PBS) for TBS for washing steps and incubations. Sections were initially incubated with anti-A1 for 30 minutes at room temperature, washed three times in PBS, incubated with antimouse IgG fluorescein isothiocyanate (Seralab) $1: 20$ in PBS with $20 \%$ normal human serum for 30 minutes at room temperature, washed three times in PBS, incubated for 20 minutes in $20 \%$ normal mouse serum, in PBS at room temperature, incubated with biotinylated EBM 11 (1:10) in PBS for 30 minutes at room temperature, washed three times in PBS, incubated in streptavidin tetramethylrhodamine (TRITC) (Seralab) at 1:20 in PBS with $20 \%$ normal human serum for 30 minutes at room temperature, washed three times in PBS, and mounted in glycerol containing 1,4-diazobicyclo $(2,2,2)$ octane (DABCO).

\section{Results}

Figure 1 shows the distribution of annexin-I in non-inflamed synovium, osteoarthritic synovium, and rheumatoid arthritic synovium. In each case, the most prominent staining was seen in the synovial lining layer, although in rheumatoid tissue CD14/CD68 elongated cells within the subintimal stroma were also strongly positive. There was generally a greater intensity of staining in the RA synovium, mainly as a result of the increased depth of the intimal layer, compared with the OA or control groups. Labelling of serial sections with cell specific CD14, CD68 or prolyl hydroxylase antibodies indicated that the majority of annexin-I staining was present in cells of the macrophage rather than fibroblast lineage (data not shown). 

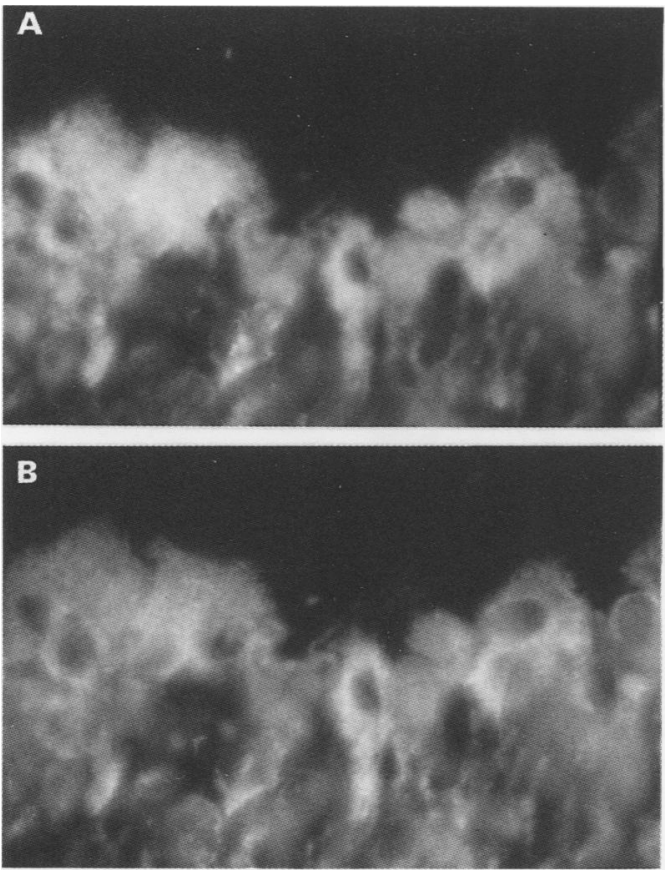

Figure 2 High power view of a section of synovial intima from a patient with rheumatoid arthritis, showing distribution of $C D 68(A)$ and annexin-I $(B)$ by immunofluorescence. It can be seen that staining for both antibodies in this section is colocalised.

This was confirmed using double immunofluorescence staining, which demonstrated that annexin-I was present on all macrophages in the tissue and only to a limited extent on other cell types. Figure 2 illustrates this with a high power view of the intimal layer of synovium from an RA patient, stained with anti-CD68 (A) and antiannexin-I (B). There is a high degree of contiguity in the pattern of staining for both antibodies.

The P11 subunit of annexin-II (calpactin-I), recognised by $\mathrm{LC} 148$, showed a distribution similar to that of annexin-I, though in addition to the staining of the macrophages of the synovial lining, marked positive staining was observed around blood vessels within RA synovium (fig 3 ).

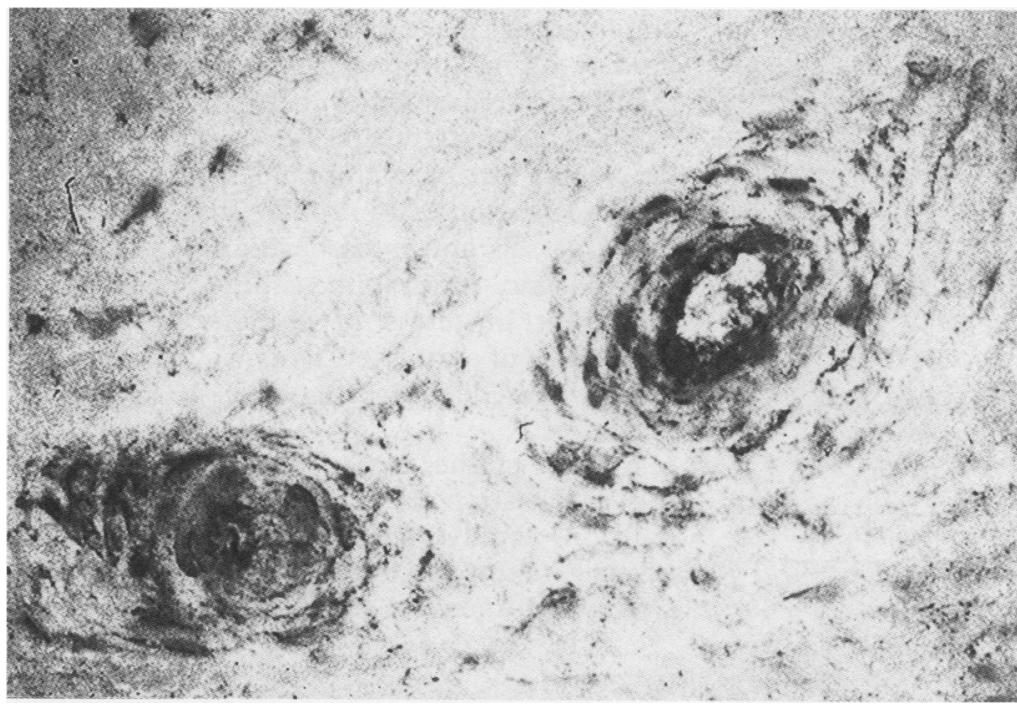

Figure 3 Annexin-II 11 subunit staining around blood vessels in rheumatoid arthritic synovium. Sections counterstained with haematoxylin.
Staining for annexin-IV and -VI was scant in normal tissue, being localised to synovial vascular endothelium (fig 4). In rheumatoid tissue, areas of lymphocytic infiltration which stained positive for the pan-T cell marker CD3 also stained strongly for annexin-VI (fig 5). A similar distribution of staining was observed for annexin-IV. There was also increased staining for both these proteins in areas of neovascularisation.

Table 1 summarises findings for the distribution of staining with the entire panel of annexin antibodies in RA synovium. This table highlights the differential pattern of distribution of annexin-I and -II to the intimal layers and annexin-IV and -VI to vascular endothelium and areas of lymphocytic infiltration. Table 2 summarises intergroup variations in staining intensity of annexins within the intimal layer, as this was the only identifiable structure which could adequately be assessed in all three groups. No significant differences were observed apart from a slight but detectable increase in annexin-IV in RA synovial intima compared with control and OA tissues.

\section{Discussion}

This histological study has demonstrated the presence of annexin-I, -II, -IV, and -VI in synovial biopsy specimens from patients with rheumatoid arthritis and osteoarthritis. These proteins were also detectable in synovium derived from non-inflamed tissues of patients with osteosarcoma. Annexin-I staining occurred predominantly in the synovial lining associated with cells of the monocyte-macrophage lineage. Annexin-II (p11 subunit) also existed predominantly in the lining layers, though there was some expression around blood vessels. Annexin-IV and -VI were mainly associated with vascular endothelium and areas of lymphocytic infiltration. This differential distribution may reflect different activities of these molecules. There were no obvious differences in the degree of cellular staining for each annexin between control and patient groups; the greater intimal depth resulting from proliferation in RA synovium increased the extent of tissue staining, rather than its intensity.

Annexin-II, -IV, and -VI may have cytoskeletal or exocytotic functions in a variety of cell types, including endothelial cells, while annexin-I and -II may be important in intracellular signal transduction pathways involved in cell differentiation. Annexin-I is of particular interest in the context of rheumatoid arthritis, as it appears to mediate at least some of the anti-inflammatory effects of corticosteroids. Increased local expression of annexin-I at the site of acute injury or inflammatory insult in response to the stress induced increase in endogenous cortisol was predicted in a recent hypothesis that these proteins act as a barrier at discrete sites around the body to suppress inappropriate inflammatory or immune responses. ${ }^{19}$ Chronic inflammation, autoimmunity, or both, could develop when this regulatory mechanism is broken by either lack of sufficient annexin-I generation, or the 


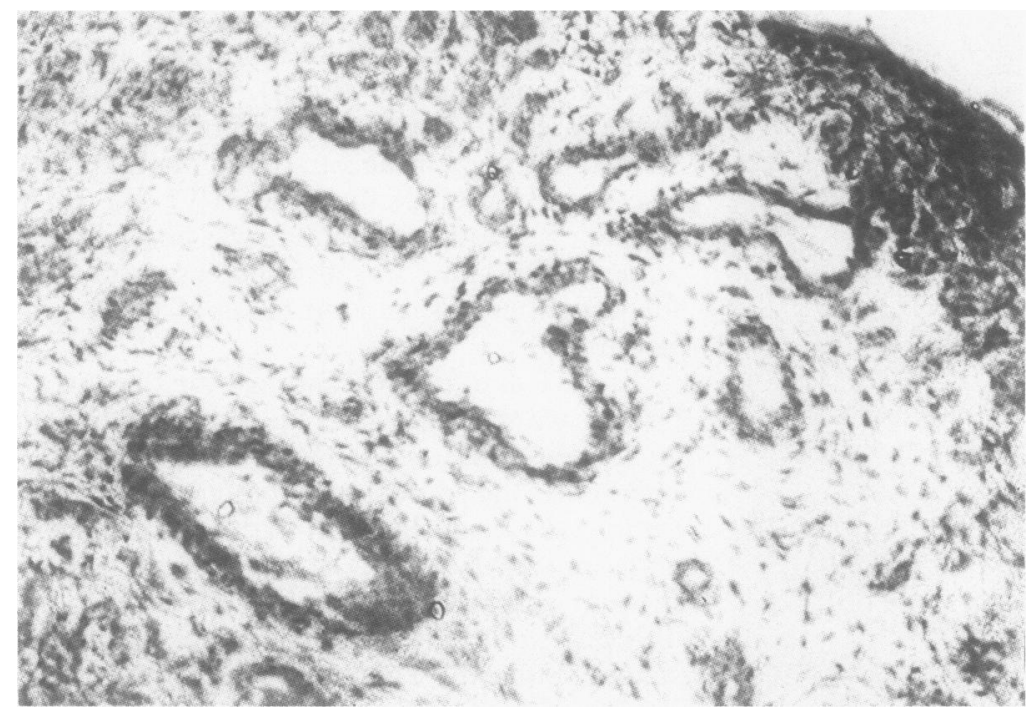

Figure 4 Annexin-IV staining around blood vessels in synovium from a normal joint. Sections counterstained with haematoxylin.

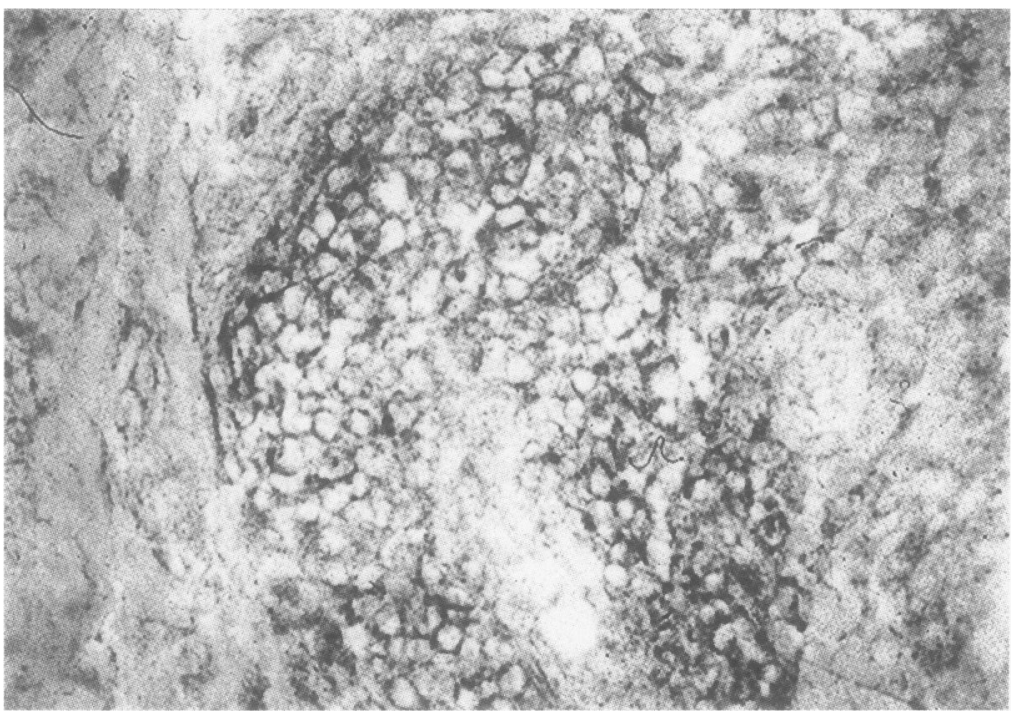

Figure 5 Annexin-VI staining associated with areas of lymphocytic infiltration within rheumatoid arthritic synovium in a non-counterstained section. Staining of lymphocyte appears to be mainly perimembranous.

Table 1 Summary of the distribution of annexin-I, $-I I(p 11),-I V$, and -VI in synovium obtained from patients with rheumatoid arthritis

\begin{tabular}{lllll}
\hline & $\begin{array}{l}\text { C68 5B5 } \\
\text { intimal layer }\end{array}$ & $\begin{array}{l}\text { CD3 } \\
\text { lymphoid areas }\end{array}$ & $\begin{array}{l}\text { CD14 CD68 } \\
\text { subintimal cells }\end{array}$ & $\begin{array}{l}\text { Vascular } \\
\text { endothelium }\end{array}$ \\
\hline Annexin-I & +++ & - & +++ & + \\
Annexin-II (p11) & ++ & - & ++ & ++ \\
Annexin-IV & + & + & + & +++ \\
Annexin-VI & + & +++ & + & +++ \\
\hline
\end{tabular}

$=$ No significant staining above background; $+=$ margin

Table 2 Summary of the expression of annexin-I, $-I I$ (p11), $-I V$, and -VI in synovial intima from patients with osteosarcoma (control), rheumatoid arthritis $(R A)$, and osteoarthritis (OA)

\begin{tabular}{llll}
\hline & Control & $R A$ & $O A$ \\
\hline Annexin-I & +++ & +++ & +++ \\
Annexin-II (p11) & ++ & ++ & ++ \\
Annexin-IV & $+/-$ & + & $+/$ \\
Annexin-VI & + & + & + \\
\hline
\end{tabular}

$-=$ No significant staining above background; $+=$ marginal but detectably positive staining; $++=$ significant staining; $+++=$ abundant, dense staining. presence of autoantibodies which may neutralise activities of the protein. Both these abnormalities have been reported previously in patients with rheumatoid synovitis. ${ }^{8} 20$

This study found that annexins, including annexin-I, are present in significant amounts within rheumatoid synovium. Annexin-I appears to be particularly associated with macrophages within the synovial lining layer. Other studies have failed to measure significant lipocortin-I in serum or plasma, ${ }^{21}{ }^{22}$ suggesting that the annexin-I is produced locally and binds rapidly to cell membranes in an autocrine or paracrine fashion. Previous studies indicate that cells of the monocyte-macrophage lineage are major producers of annexin$\mathrm{I}$, and this would account for the distribution pattern observed in synovium. ${ }^{23}$ The results of this study also suggest that there is no significant deficiency in annexin-I levels in rheumatoid tissue. However, amounts of protein demonstrated immunochemically do not necessarily indicate that the protein is in a functional state. Annexin-I could be rapidly degraded by proteolytic enzymes or reactive oxygen species within the joint, rendering it inactive. Alternatively, phosphorylation of tyrosine residues situated in the $\mathrm{N}$-terminal domain of the molecule has been suggested as a mechanism of inactivation. ${ }^{24}$ Autoantibodies to the molecule might also have a neutralising effect. Although IgG and IgM antibodies have been reported to be present in the serum of $R A$ patients receiving oral corticosteroids, ${ }^{20}$ there is as yet no evidence of their presence in synovial fluid. Also, expression of lipocortin-I 'receptors' on peripheral blood monocytes and neutrophils could be an important factor, as cells from rheumatoid patients exhibit only $10 \%$ of the lipocortin binding capacity of controls. Thus even if active annexin-I were present at the inflammatory focus, phagocytic cells migrating into these areas might not have the necessary signal transduction system to downregulate their inflammatory activities. ${ }^{19}$

Despite exhibiting $>50 \%$ amino acid sequence homology with annexin-I, other members of the family demonstrate diverse physiological functions. It is becoming apparent that the calcium dependent phospholipid binding properties of annexins may manifest themselves in regulation of endocytotic and exocytotic processes within cells via the regulation of membrane fusion events. ${ }^{11}$ The localisation of annexin-IV and -VI around blood vessels and in association with areas of lymphocytic infiltration could therefore be important in terms of granule release and secretion of soluble factors, or through receptor mediated phagocytic or pinocytic processes.

Further studies are in progress to examine the localisation of other members of the annexin family within synovium, and to investigate the effects of intra-articular corticosteroid treatment on annexin expression.

This work was supported by grants G0054, G0083 (NJG) and E0048, E0056 (JCWE) from the Arthritis and Rheumatism Council for Research (UK). We are grateful to Dr Jeffery 
Browning of Biogen Corp, Cambridge, MA, USA for generously providing the monoclonal antibody $1 \mathrm{~B}$ for these studies.

1 Munck A, Guyre P M, Holbrook N J. Physiological functions of glucocorticoids in stress and their relation to pharmacological actions. Endocr Rev 1984; 5: 25-44.

2 Boumpas D T, Paliogianni F, Anastassiou E D, Balow J E. Glucocorticosteroid action on the immune system: molecular and cellular aspects. Clin Exp Rheumatol 1991; 9: 413-23.

3 Goldstein R A, Bowen D L, Fauci A S. Adrenal corticosteroids. In: Gallin J I, Goldstein I M, Snyderman R, eds. Inflammation: basic principles and clinical correlates, 2nd edn. New York: Raven Press, 1992; 1061-80.

4 Raynal P, Pollard H B. Annexins: the problem of assessing the biological role for a gene family of multifunctional the biological role for a gene family of multifunctional Biophys Acta 1994; 1197: 63-93.

5 Flower R J. Lipocortin. Prog Clin Biol Res 1990; 349: 11-25.

6 Rothwell N J, Flower R J. Lipocortin-I exhibits novel actions, providing clinical opportunities. Trends Pharmacol Sci 1992; 13: 45-6.

7 Vishwanath B S, Frey F J, Bradbury M, Dallman M F, Frey B $M$. Adrenalectomy decreases lipocortin-I messenger ribonucleic acid and tissue protein content in rats. Endocrinology 1992; 130: 585-91.

8 Morand E F, Jefferiss C M, Dixey J, Mitra D, Goulding N J. Impaired glucocorticoid induction of mononuclear leukocyte lipocortin-1 in rheumatoid arthritis. Arthritis leukocyte lipocortin-1 in
Rheum 1994; 37: 207-11.

9 Goulding N J, Luying P, Jefferiss C M, Rigby W F C, Guyre $P$ M. Specific binding of lipocortin 1 (Annexin I) to monocytes and neutrophils is decreased in rheumatoid arthritis. Arthritis Rheum 1992; 35: 1395-7.

10 Ali S M, Geisow M J, Burgoyne R D. A role for calpactin in calcium-dependent exocytosis in adrenal chromaffin cells. Nature 1989; 340: 313-5.

11 Zaks W J, Creutz C E. Evaluation of the annexins as potential mediators of membrane fusion in exocytosis. f Bioenerg Biomembr 1990; 22: 97-120.
12 Zaks W J, Creutz C E. $\mathrm{Ca}^{2+}$-Dependent annexin selfassociation on membrane surfaces. Biochemistry 1991; 30: 9607-15.

13 Rocha V, Lozano J J, Haindl A H. Evidence for differential localization of annexin VI during mammary secretory differentiation. Biochem Soc Trans 1990; 18: 1110-3.

14 Tait J F, Gibson D, Fujikawa K. Phospholipid binding properties of human placental anticoagulant protein-I, a member of the lipocortin family. $\mathcal{F}$ Biol Chem 1989; 264: 7944-9.

15 Pollard H B, Guy H R, Arispe N, Delafuente M, Lee G, Rojas E M. Calcium-channel and membrane-fusion activity of synexin and other members of the annexin gene family. Biophys f 1992; 62: 15-8.

16 Arnett F C, Edworthy S M, Bloch D A, et al. The American Rheumatism Association 1987 revised criteria for the classification of rheumatoid arthritis. Arthritis Rheum 1988; 31: 315-24.

17 Franklin W A, Mason D Y, Pulford K, et al. Immunohistological analysis of human mononuclear phagocytes and dendritic cells by using monoclonal phagocytes and dendritic cells by

18 Hoyhtya M, Myllyla R, Siuva J, Kivirkko K L, Tryggvason K. Monoclonal antibodies to human prolyl-4hydroxylase. Eur f Biochem 1984; 141: 477-82.

19 Goulding N J, Guyre P M. Regulation of inflammation by lipocortin I. Immunol Today 1992; 13: 295-7.

20 Podgorski M R, Goulding N J, Hall N D, Flower R J, Maddison $\mathrm{P}$ J. Autoantibodies to lipocortin 1 are associated with impaired corticostero rheumatoid arthritis. $₹$ Rheumatol 1992; 19: 1668-71.

21 Goulding N J, Godolphin J L, Sharland P R, et al. Antiinflammatory lipocortin 1 production by peripheral blood leucocytes in response to hydrocortisone. Lancet 1990; 335: $1416-8$.

22 Christmas P, Callaway J, Fallon J, Jones J, Haigler H T. Selective secretion of annexin 1 , a protein without a signal sequence, by the human prostate gland. $\mathcal{F}$ Biol Chem 1991; 266: 2499-507.

23 Fava R A, McKanna J, Cohen S. Lipocortin I (p35) is abundant in a restricted number of differentiated cell types in adult organs. f Cell Physiol 1989; 141: 284-93.

24 Pepinsky R B. Phosphorylation of lipocortin-1 by the epidermal growth-factor receptor. Methods Enzymol 1991; 291: $260-72$. 